\title{
Bridging the Gap between Instructional Design and Double Loop Learning
}

Citation for published version (APA):

Spoelstra, H., Rusman, E., Van Bruggen, J., Koper, R., \& Matera, M. (2008). Bridging the Gap between Instructional Design and Double Loop Learning. International Journal of Web-Based Learning and Teaching Technologies, 3(1), 79-89. https://doi.org/10.4018/jwltt.2008010108

\section{DOI:}

10.4018/jwltt.2008010108

Document status and date:

Published: 01/01/2008

Document Version:

Peer reviewed version

Please check the document version of this publication:

- A submitted manuscript is the version of the article upon submission and before peer-review. There can be important differences between the submitted version and the official published version of record. People interested in the research are advised to contact the author for the final version of the publication, or visit the DOI to the publisher's website.

- The final author version and the galley proof are versions of the publication after peer review.

- The final published version features the final layout of the paper including the volume, issue and page numbers.

Link to publication

\section{General rights}

Copyright and moral rights for the publications made accessible in the public portal are retained by the authors and/or other copyright owners and it is a condition of accessing publications that users recognise and abide by the legal requirements associated with these rights.

- Users may download and print one copy of any publication from the public portal for the purpose of private study or research.

- You may not further distribute the material or use it for any profit-making activity or commercial gain

- You may freely distribute the URL identifying the publication in the public portal.

If the publication is distributed under the terms of Article 25fa of the Dutch Copyright Act, indicated by the "Taverne" license above, please follow below link for the End User Agreement:

https://www.ou.nl/taverne-agreement

Take down policy

If you believe that this document breaches copyright please contact us at:

pure-support@ou.nl

providing details and we will investigate your claim.

Downloaded from https://research.ou.nl/ on date: 26 Apr. 2023 


\section{COVERPAGE}

Title:

Bridging the gap between instructional design and double loop learning

Authors:

Howard Spoelstra *

Maristella Matera \#

Ellen Rusman *

Jan van Bruggen *

Rob Koper*

\section{Email addresses:}

howard.spoelstra@ou.nl

matera@elet.polimi.it

ellen.rusman@ou.nl

jan.vanbruggen@ou.nl

rob.koper@ou.nl

\section{Affiliations:}

* OTEC, Open University of the Netherlands, Valkenburgerweg 177, Heerlen, the Netherlands

\# Politecnico di Milano, Via Ponzio, 34/5 20133, Milano, Italy

About the authors:

Howard Spoelstra studied Philosophy and received a Master Degree in Knowledge Management in 2001. In 1997 he joined the Open University of the Netherlands as an assistant professor at the School of Science where he was involved in the development of the "Virtual Company" educational scenario for competence building in virtual teams. In 2001 he joined the Educational Technology Expertise Centre of the Open University of the Netherlands. His work there focuses on research and development of collaborative learning methods, like learning networks and CSCL environments and online teaching support tools. He is the co-editor of "Learning Networks using Learning Design. A first collection of papers" (Open Universiteit Nederland, 2004)

Maristella Matera is assistant professor at Politecnico di Milano, where in 2000 she received a $\mathrm{PhD}$ in Computer Science Engineering. She has been awarded several fellowships for supporting her research work at Italian and foreign institutions; in particular, she was visiting researcher at the GVU Center (Georgia Institute of Technology, USA). Her research focuses on design methods and tools for Web applications, with particular emphasis on context-awareness, Web-based e-learning, Web usage mining, usability and accessibility. She is author of about 70 papers and is 
co-author of the book "Designing data-intensive Web Applications" (Morgan

Kaufmann publisher, 2002).

Ellen Rusman holds a Msc. in Educational Science and Technology at the University of Twente in the Netherlands. She spend several months as a student at the Centre for Studies in Advanced Learning Technology (C-SALT) at Lancaster University and has been an educational designer at the Educational Technology Expertise Centre of the Open University of the Netherlands since 1998. She designs environments for learning, information and knowledge management. Her fields of expertise are the nurturing of networks for learning and working and educational design for computer supported collaborative learning.

Recently she started to combine her work as an educational designer with in-depth research within a $\mathrm{PhD}$ trajectory on trust. Interpersonal trust is seen as an important determining factor for the successfulness of human collaboration. In this research she explores how members of a virtual team estimate each others trustworthiness and how they can be supported while making these estimations in mediated environments.

Jan van Bruggen is an associate professor at the Educational Expertise Center (Otec) of the Open University of the Netherlands. He holds a PhD in educational technology. He conducted experimental research in cognitive and metacognitive reading and studying strategies. At the University of Amsterdam (COWO and SCO-Kohnstamm Institute) he co-pioneered one of the first firms in computer-based training and distance training for major Dutch financial institutions. He was involved in several European projects in Esprit (Eurohelp) as well as projects in Delta, where he was project leader of the Delta project ACES. In 1992, he joined the Open University of the Netherlands where he developed knowledge-based systems to support students and staff in curricular planning. Further, he was involved in the development of the "Virtual Company" educational scenario for competence building in virtual teams. At Otec he is involved in the Technology Development Program and holds the position of Deputy Dean in the master degree program "Active Learning".

Rob Koper is professor in educational technology and director of RTD into learning technologies with the Open University of the Netherlands Educational Technology Expertice Centre. He was, among other things, responsible for the development of the Educational Modelling Language (the predecessor of IMS Learning Design). His research focuses on self-organised distributed learning networks for lifelong learning, including RTD into software agents, educational semantic web, interoperability specifications and standards. A recent book he edited with W. Jochems and J. van Merriënboer is "Integrated eLearning" (2004, London: RoutledgeFalmer). 
Bridging the Gap between Instructional Design and Double Loop Learning

\begin{abstract}
The implementation of double loop learning based educational scenarios in instructional designs in workflow-like e-learning systems appears to be showing a gap; whereas the former assumes that processes can be reflected upon and can be modified or amended by the learners, the latter only predefines a limited set of rigid instructional processes.. However, an important advantage of instructional designs implemented in workflowlike e-learning systems using modelling standards is the ease with which they can be exchanged with other (educational) institutions. The workflow environment described here aims to make learner reflection and change to instructional processes feasible while maintaining portability. We present a description of the implementation of the pedagogical scenario of the "Virtual Company" in our workflow environment that makes use of dynamic workflow processes. Learners are provided with process building blocks, called "atomic actions" which they can use to create and revise processes "on the fly", thus supporting double-loop learning.
\end{abstract}

\title{
Introduction
}

The COOPER project (Collaborative Open Environment for Project Centered Learning) [1] aims to deliver a learning and working environment for virtual teams whose members are geographically dispersed. The members have different backgrounds and competencies, which they use to work and learn together on projects that aim to solve complex, ill-structured problems. We want to achieve this through the use of a standards-based workflow system and a pedagogical scenario that uses double loop learning extensively.

The COOPER environment is a web-based working and learning environment that is created with the Webratio computer aided software engineering tool [4], that uses standards like the Web Markup Language [5] and Business Process Modeling Notation [6]. The resulting environments like the COOPER environment (including its pedagogical scenarios) can be easy exchanged with other (educational) institutions. The educational scenario we focus on is the Virtual Company scenario [2,3], which previously has only been implemented using non-workflow based project support tools, due to lack of support for flexible process support in workflow systems.

An example of an implementation of the Virtual Company educational scenario is InCompany Milieuadvies, a virtual environmental consultancy firm in which it is attempted to fully integrate learning and working in a distance teaching environment. This is unlike case-based and problem-based approaches in higher education, where the aspect of working generally is lacking. In InCompany Milieuadvies we try to generate a networked learning environment that resembles an authentic professional situation. Students working in InCompany Milieuadvies address real orders on behalf of real external customers and deliver real products. The quality of their work and learning advancements are assessed based on real world criteria. Therefore the virtual environmental consultancy is not an extended role-playing game, which usually represent self-contained business simulations. InCompany MilieuAdvies has been running multiple projects a year from 1997. It is now a required course at the end of the Bachelor phase at the School of Science of the Open University of the Netherlands. The Cooper collaboration environment described in this paper is currently used by institutions involved in the Cooper project [1]: ALaRI, a master programme offered by 
the Università della Svizzera Italiana; ASP (Alta Scuola Politecnica), a school for young talents founded by Politecnico di Milano and Politecnico di Torino; and CoWare, a leading supplier of electronic design automation software and services.

The main educational aims of the Virtual Company are: a) personal professional development through rapid and efficient transfer of acquired knowledge and skills to professional practice, b) development of domain knowledge and skills, combined with the social, communicative and organizational skills required for teamwork and c) an explicit and critical reflection on the working and learning processes and a transfer of valuable experiences to organizational memory.

Like in other workflow systems, the COOPER environment is modelled at design-time while users work in run-time. However, to be able to support double loop learning [7] we introduce the novel concept of "atomic actions". Atomic actions are small independent process building blocks students can use to build, modify or re-arrange work processes in run-time.

\section{Instructional design in e-learning systems}

The support of the processes of collaborative work in instructional design based elearning systems is an important challenge. Instructional process design for e-learning systems can be approached in analogy to the design process in workflow systems. These workflow systems deal with collections of tasks that are organized to accomplish some business process [16], tying processes, people and resources together in dependent process steps. In the educational domain an influential model following this approach is IMS Learning Design [21].

These workflow systems seem suitable candidates for managing the modelling of collaborative work processes. In general, workflow management systems strictly separate design and execution of a workflow and they do so for good reasons: One would rather avoid users tampering with, for example, financial transaction flows. In educational environments however, this separation prevents learners from learning to improve processes that they are involved in. As our aim is to support highly dynamic processes e.g., the solving of ill-structured problems, we are challenged to model processes that can hardly be completely predefined and/or exhibit an explosive number of alternatives, thus escaping the ability to being fully modelled [8]. Consider, for example, how one could support the various stages and topics of solving ill-structured problems, and the different conversational and representational demands associated with each of them, where users may switch between stages and topics they address (Van Bruggen, Boshuizen and Kirschner) [18]. A current solution to the inability to fully model a process in e.g., workflow systems or IMS Learning Design, is to put the current process "on hold", then defer the users to a Computer Supported Collaborative Work environment in which to solve the problem, and to return control to the workflow system when done [19]. This approach, however, only circumvents the actual problem of not enabling users to solve ill-structured problems inside the workflow system.

\section{Implementing double-loop learning}

The notions of single and double-loop learning originate from organizational management and learning theory [20]. Single-loop learning emphasises the detection and correction of errors within a given set of governing variables e.g., mission, vision, 
strategy and systems used in a company. Double-loop learning, however, also involves questioning the governing variables themselves and can result in radical changes such as the revision of systems, alterations in strategy and so on (see fig 1). [17]

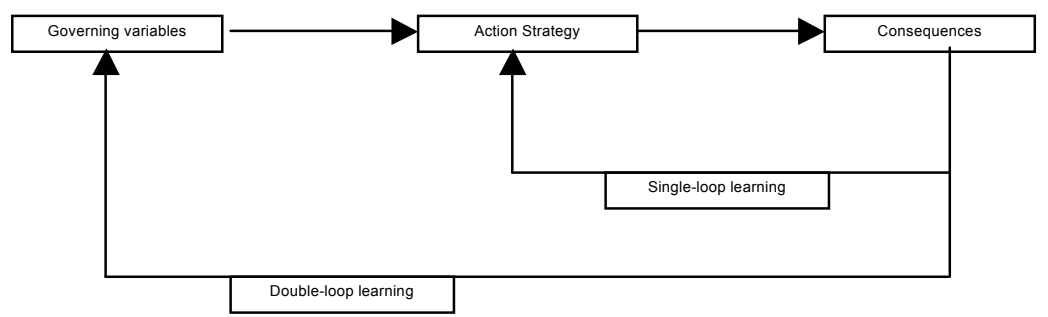

Fig. 1 Single and double loop learning

With the implementation of double loop learning principles in workflow systems the picture becomes even more complicated because double loop learning entails that the (pre)defined processes should be adaptable or amendable. Unfortunately common practice in workflow design separates design-time (analysis and implementation of the process to be modelled) from run-time (the instantiation of the workflow for the actual users). Usually process changes can only be accomplished by modifying a corresponding workflow schema in design-time. However, as argued, to be able to implement double-loop learning it is important that such changes can be conducted inside the run-time environment without causing inconsistencies and errors because of unfulfilled dependencies between process steps. [9]

So, in order to implement double loop learning we provide students with an environment that supports the evaluation of working and learning processes of individuals, their team and the organization [10] in which they operate. The results of these evaluations should be allowed to be fed back into the different levels of the organization, changing work processes and organization aspects. The Virtual Company educational design implements these double loop learning features in that students have an organizational role to fulfil in the processes in the virtual company. In that role they solve ill-structured problems from real clients in a real, but virtualized, company in order to expand their (collective) expertise in a professional setting. In doing so, they gain competence in the form of personal learning, team learning, organizational learning, knowledge management and the development of organizational competencies. $[3,11]$

The Virtual Company design consists of several phases that students, teams and the Virtual Company go through:

0 . Design the Virtual Company

1. Project development: Projects are acquired and developed

2. Project start/planning: Students apply for jobs, and state their learning goals in a personal development plan; The coach defines teams based on available projects and student preferences

3. Project execution/quality control: Based on a project work plan students perform the project in a team, but also work on personal learning goals 
4. Project end/delivery of results: Project results are delivered to the customer and to the Virtual Company (as lessons learned reports)

5. Consolidation of results: The personal, team and company performance is reviewed, and, if needed, actions are defined to improve performance.

(The phases 0,1 and 5 can be removed from the Virtual Company design which leads to an environment that supports Virtual Projects that are not embedded in a company setting. Although this limits the possibilities for DLL, it still retains valuable learning opportunities for reflection and process changes on the personal and team level. Although the Company environment is missing, the project teams still deliver lessons learned, thus enabling the educational institution to fine-tune the educational environment the projects run in.)

In the Virtual Company design, we discern three double loop learning cycles: the personal development cycle, the team development cycle and the company development cycle. These development cycles are depicted in Figures 1,2 and 3.

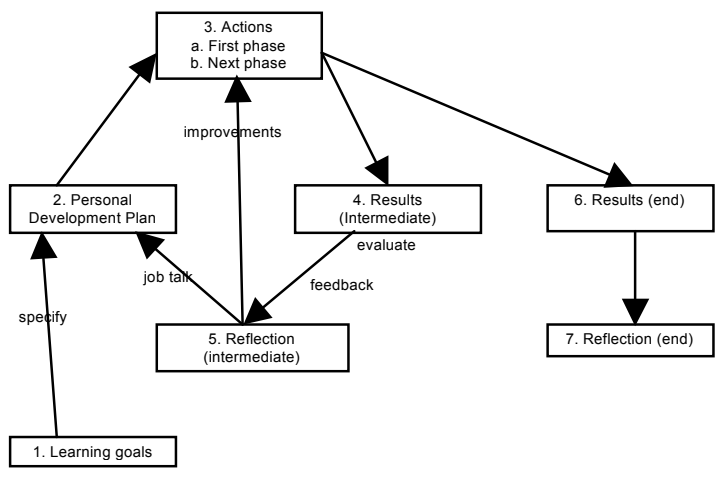

Figure 2: Personal development cycle

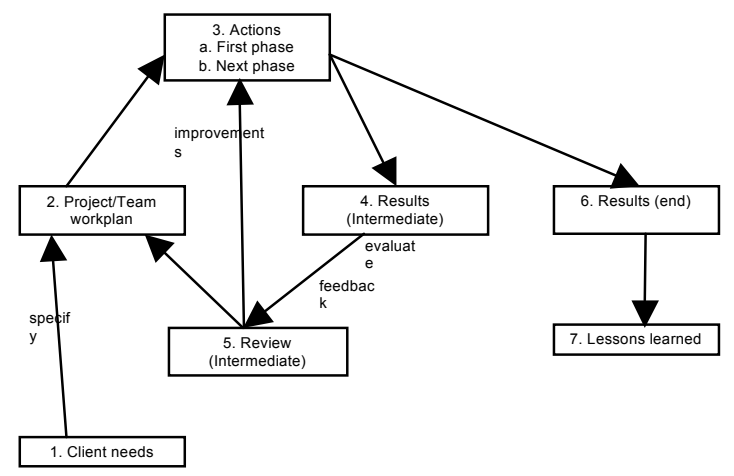

Figure 3: Team development cycle 


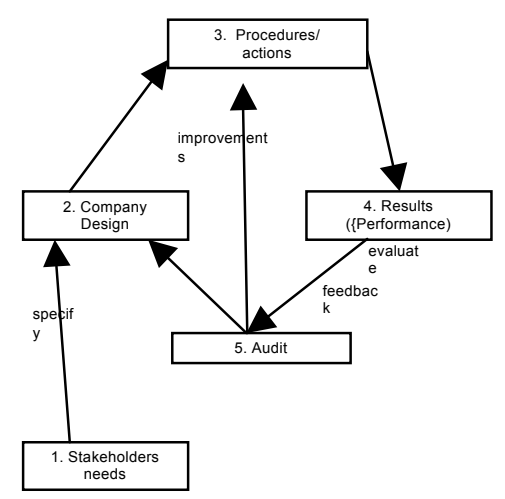

Figure 4: Company development cycle

Activities depicted in figures 2 and 3 are:

1. Learning goals are defined, also based on possible learning opportunities in the client needs

2. The personal development plan is made, in conjunction with the team work plan

3. Actions are performed, based on the initial personal development plan and team project plan.

4. Results are delivered to the Virtual Company and the customer.

5. Reflection on both personal development and team development can lead to adjustments in the personal development and team work plan, thus changing the actions to be performed.

6. The project end result is delivered.

7. Final personal and team reflections on product and process are performed; lessons learned are made available for other project teams and the company to reflect on.

Activities depicted in figure 4 are:

1. An analysis of stakeholders needs is performed

2. A company is designed to meet those needs

3. Procedures and actions are defined that will guide performance and quality

4. Results are achieved by workers following procedures

5. Audits are organised to review the envisioned company/actions/results in relation to the stakeholders needs and performance standards

For figures 2, 3 and 4 it is in the cycle of steps 2, 3, 4 and 5 that double-loop learning takes place and students can decide to adjust e.g., the personal development plan, team project plans or assessment criteria, thus leading to changes in their working and learning environment. For figure 4, the results of activity 7 in the team development cycle (describing lessons learned) are, together with other stakeholders needs, the basis of a company audit and the subsequent improvements in company design and its actions. Please note that within a project the cycle is performed multiple times for the student and the team (as often as the project plan prescribes) while the cycle is only performed once per project on the company level.

Until now, the Virtual Company design was implemented with readily available project support tools, like document sharing environments. A major drawback of this approach 
is that it does not allow for automating processes: There is no system support for automatic checking whether process steps are completed; What tasks are up next for the team or the individual student, and there is no automatic logging of activities. Therefore, the student and team work processes and the progress had to be monitored by hand. In such a setting, the Virtual Company work processes were described in documents or static web pages, not automated, so each instantiation of a Virtual Company had to be designed from the bottom up [14].

Table 1 sums up the discrepancies between the characteristics of ID in workflow systems and the required characteristics to support DLL

Table 1: Discrepancies between current ID in workflow systems and DLL

\begin{tabular}{|l|l|}
\hline $\begin{array}{l}\text { Instructional Design (ID) in workflow } \\
\text { systems }\end{array}$ & $\begin{array}{l}\text { Double loop learning (DLL) in } \\
\text { workflow systems }\end{array}$ \\
\hline Mainly aimed at static processes & Requires support for dynamic processes \\
\hline $\begin{array}{l}\text { Separation of design and execution of } \\
\text { workflows }\end{array}$ & $\begin{array}{l}\text { Design and execution/adaptation of } \\
\text { processes, based on reflection on the } \\
\text { effectiveness of the process, is united in } \\
\text { the learner. }\end{array}$ \\
\hline $\begin{array}{l}\text { Automation of predictable and repetitive } \\
\text { processes }\end{array}$ & Require flexible process support \\
\hline Work process steps show dependencies & $\begin{array}{l}\text { Work process steps show a lack of pre- } \\
\text { structure }\end{array}$ \\
\hline Designs are portable to other systems & Need to redesign new implementations \\
\hline $\begin{array}{l}\text { Work processes are predefined at design- } \\
\text { time }\end{array}$ & $\begin{array}{l}\text { Work processes can be redefined in run- } \\
\text { time }\end{array}$ \\
\hline
\end{tabular}

We have described the phases we distinguish in the workings of a Virtual Company, how these were implemented in the past, and what we envision is required for implementing double loop learning in a Virtual Company educational scenario, using work flow based systems. We will now describe our implementation using the Cooper environment

\section{The Cooper environment}

The Cooper working environment is developed with the use of Webratio, a computer assisted software engineering tool that allows the visual modelling of applications with the Web Modeling Language. Webratio enables the automatic generation of code starting from the visual schemas generated during design. Up to now, Web Modeling Language and Webratio could only cope with the design of static workflows [12], i.e., processes that are specified at design-time and are then delivered to the users by means of a Web application supporting the execution of the pre-planned process activities. Webratio and Web Modelling Language allow designers to visually specify workflows at a high level of abstraction using the Business Process Modelling Notation. It also provides a set of model transformations from Business Process Modelling Notation workflow diagrams to Web Modelling Language hypertext diagrams that allow fast generation of web site skeletons implementing the specified business process [13]. 
As argued earlier, static workflows alone cannot support the Virtual Company educational design in full because in this design students should be presented with a collaboration environment that is adaptable in run-time. In fact, once the application supporting the static workflow execution is produced and deployed, it becomes difficult (or even impossible) to modify the process. Therefore, we introduce a more flexible mechanism, called atomic actions, that allow students to define and/or adapt their dynamic cooperation processes at run-time.

We developed this mechanism by firstly analyzing the project execution phase in several project methodologies for reoccurring activities. Secondly, we broke down these reoccurring activities into Atomic Actions, from which we developed an Atomic Actions library.

Atomic Actions:

1. Are performed on a regular basis

2. May involve individual or group activities and may be started by an individual or a group

3. Have a clear starting and ending point, serving a (very) small goal in the project process

4. Use one or more of the services that are integrated in the COOPER platform

5. Can easily be composed into dynamic processes supporting the completion of cooperative tasks involving several actors

The Atomic Actions library consists of atomic actions directly aimed at the process of running the project and of atomic actions that support the communication processes used to collaborate virtually.

They may be seen as (very) small pieces of workflow that can be "stitched" together at will, while retaining the changeability of the so constructed process.

The Atomic Actions are then modelled in the environment. This enables us to allow students, when analyzing the tasks in their project, to use these "Atomic Actions" as building blocks to model their own working and communication processes, and change these if reflection on the processes so requires.

Although our work in the Cooper project also involves modelling the entire company environment through the use of Webratio, our current list of atomic actions consists of actions to be used only in the project phases 3 and 4 (see above). A provisional list of these atomic actions is presented in Table 2.

Table 2: Atomic Actions classified by the collaborative activity they relate to.

\begin{tabular}{ll}
\hline Project Activities & Atomic Actions \\
Define project method & $\begin{array}{l}\text { Define a task } \\
\text { Assign a task }\end{array}$ \\
& Define a project milestone \\
& Define a deliverable \\
Organize review & Create a review report \\
& Assign a resource to (a) \\
& reviewer(s) \\
& Submit a review on a resource \\
Organize assessment & Define an assessment criterion \\
\hline
\end{tabular}




\begin{tabular}{lll}
\hline & $\begin{array}{l}\text { Define a performance indicator } \\
\text { Plan an assessment } \\
\text { Upload a document } \\
\text { Publish a document } \\
\text { Roject support }\end{array}$ & \\
activities & & \\
Communication & Open a VoIP* meeting & Open a co-browsing activity \\
& Join a VoIP meeting & Moderate a co-browsing \\
& Make a VoIP call & activity \\
& Create a chat room & Join a co-browsing activity \\
Open a chat session & Open a forum \\
& Moderate a chat session & Open a forum thread \\
& Join a chat session & Moderate a forum thread \\
Define a voting question & Send a forum thread message \\
& Submit a vote & Define a Wiki \\
Summarize voting results & Modify a Wiki page \\
& Open a video conference & \\
Moderate a video conference & \\
& Join a videoconference & \\
\hline
\end{tabular}

*: Voice over IP

An example of how a working process is created and can be changed is shown below:

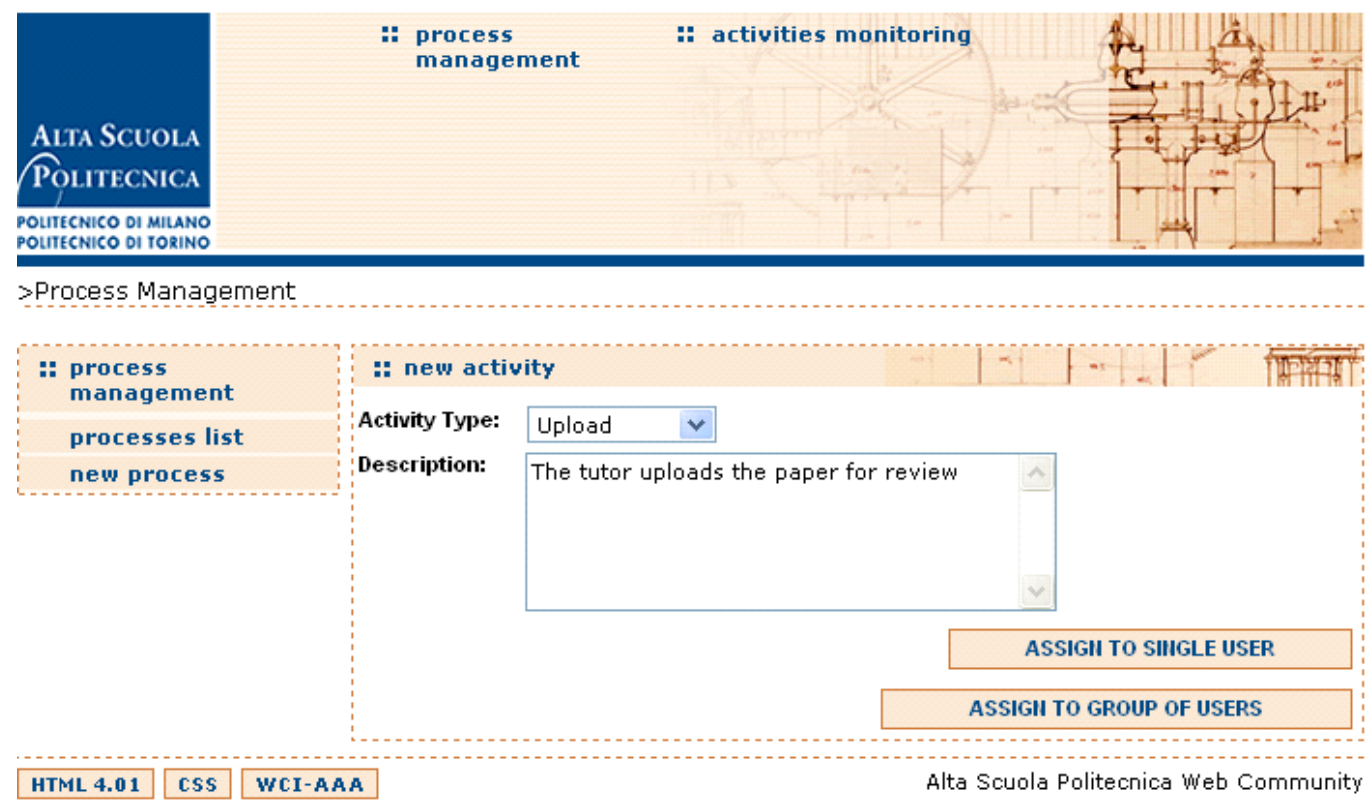




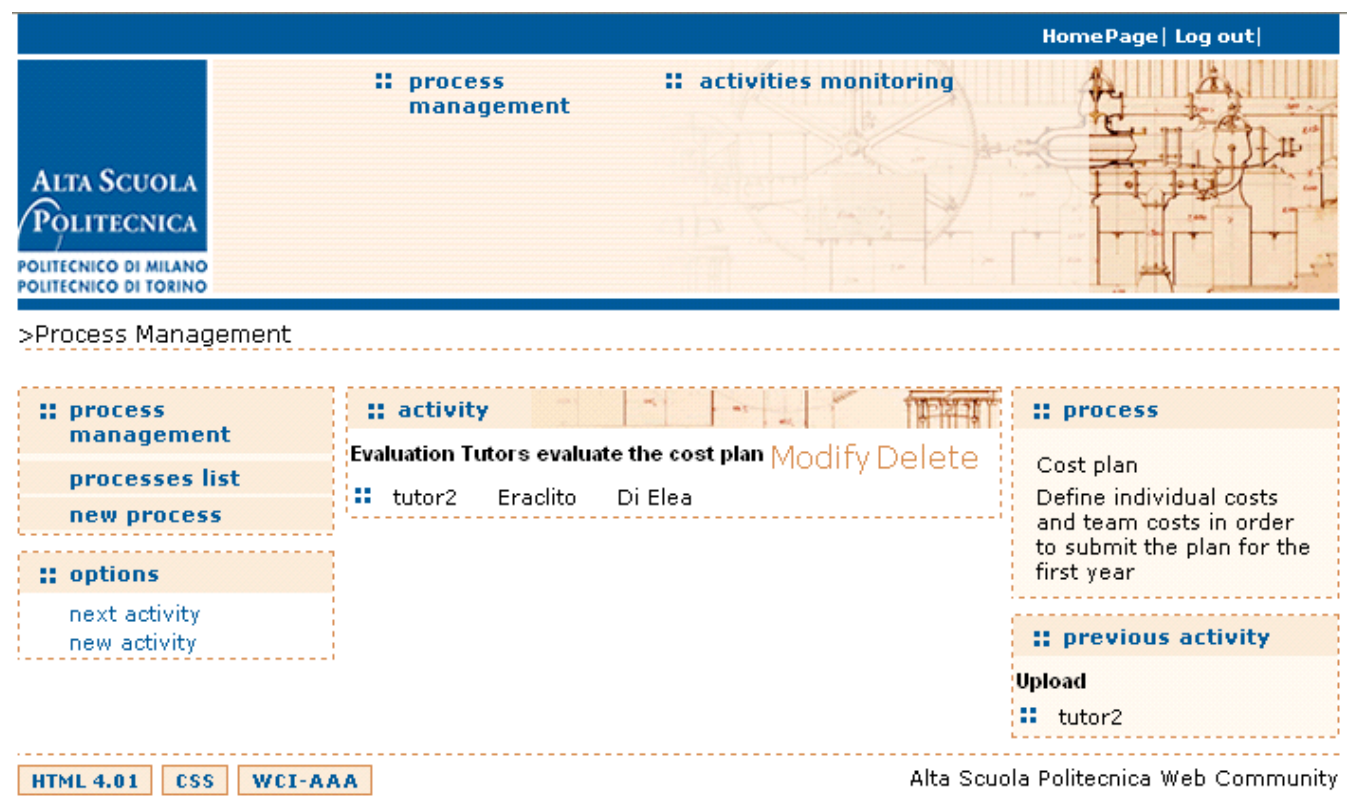

Figs 2a and 2b. Definition and alteration of a processes

In the COOPER environment a work process can be considered as a sequence of phases, in which each phase is delimited by work flow synchronization points. These points form possible constraints in the control of the process flow. The definition of a work process therefore proceeds in phases. For each phase the selection of one or more atomic actions is required (corresponding to the phase' activities).

Figure $2 \mathrm{a}$ shows the page where a tutor in run-time defines a process by selecting an atomic action (e.g., upload of a document) for inclusion in a process phase, and describes the purpose of the activity by entering a short textual description. The activity is then assigned to the team member(s) that should accomplish it. Activities can be assigned to single users or to a group of users. In the last case, the activity definition also requires the user to specify the type of parallelism governing the execution of the parallel activity. For example, a user may choose whether all team members are asked to execute the activity, or whether at least one of them should execute it. Finally, the definition of a single activity may also require the association of resources for managing document flows, as it often occurs in cooperation processes.

After a process has been defined it is possible to revise its definition (as is shown in figure $2 b$ ) by modifying or deleting its activities or the assignment of activities to users. As long as a process is not running any activity can be modified. Once the work process is running modifications are only allowed on activities not yet started.

The Cooper environment also supports process templates, i.e., process models, which can be designed independent from specific project teams and specific actors. The template only defines the temporal sequence of activities and possible activity synchronization constraints, omitting the assignment of activities to users. Once defined, these templates can be used for starting new processes that only require the selection of the actors for each activity in the template.

So, using process templates enables us to present students with a predefined set of templates of activities (useful for less experienced project members). If we choose not 
to use templates, we can offer users a "clean slate" on which to model and adapt their own processes (for students well acquainted with project work). Both options retain the flexibility to make "on the fly" changes, thus bridging the gap between Instructional Design and double loop learning.

\section{Discussion}

Instructional scenarios as implemented in work flow systems and double loop learning can be brought together using Atomic Actions. The notion of Atomic Actions is not limited to the COOPER environment alone. Research into an extension of other workflow based e-learning system, like IMS LD, may also be considered. A current limitation of our solution is that, although the use of Atomic Actions in process design offers students flexibility, not all dependencies between process steps are resolved. Further analysis of these dependencies and ways to avoid them is required. A broader list of Atomic Actions and the modelling of other educational scenarios in the Cooper environment are also subject to further research.

the novel approach to implement adaptability (required to be able to implement the chosen pedagogical design) in otherwise rigid workflow systems. In our view the results are of importance for educational institution seeking implementation of double loop learning scenarios and for workflow designers, looking for more flexible solutions to complex process problems.

Acknowledgements: This article is sponsored by the COOPER Project that is funded by the European Commission's $6^{\text {th }}$ Framework Programme, priority 2 IST. Contract no.: 027073 (www.cooper-project.org)

\section{References}

[1] The COOPER project: http://www.cooper-project.org

[2] M. Bitter, P. Sloep and D. Jansen (2003) Learning to change: The Virtual Business Learning approach to professional workplace learning. Educational Technology \& Society 6 (1), 2003.

[3] W. Westera and P.B. Sloep (1998) The Virtual Company: Towards a Self-Directed, Competence-Based Learning Environment. Educational Technology, the magazine for managers of change in education, 38 (1), 32-38.

[4] Webratio: http://www.webratio.com/page18.do

[5] WebML: http://www.webml.org/webml/page1.do

[6] BPMI. Business Process Management Language, http://www.bpmi.org.

[7] C. Argyris and D.A. Schön (1996). Organizational learning II: theory, method, and practice, Reading, MA: Addison Wesley.

[8] P. Mangan and S. Sadiq. On Building Workflow Models for Flexible Processes. ACM International Conference Proceeding Series; Vol. 18, 2002.

[9] S. Rinderle, M. Reichert and P. Dadam. Flexible Support of Team Processes by Adaptive Workflow Systems. Distributed and Parallel Databases Volume 16, Number $1 /$ July, 2004 pp. 91-116

[10] C. Argyris and D.A. Schön (1974). Theory in Practice, San Francisco: Jossey-Bass.

[11]W. Westera, P.B. Sloep and J. Gerrissen (2000). The Design of the Virtual Company; Synergism of Learning and Working in a Networked Environment. Innovations in Education and Training International 37 (1), 24-33. 
[12] M. Brambilla, S. Ceri, P. Fraternali, I. Manolescu. Process Modeling in Web Applications. ACM TOSEM (to appear).

[13] M. Brambilla. Generation of WebML Web Application Models from Business Process Specifications. Demo at the 6th International Conference on Web Engineering (ICWE2006), July 2006, Palo Alto, CA, USA.

[14] Incompany MilieuAdvies http://www.incompany-milieuadvies.nl/icm/index.asp [16] D. Georgakopoulos, M. Hornick and A. Sheth. An overview of workflow management: From process modeling to workflow automation infrastructure. Distributed and Parallel Databases, Volume 3, Number 2 / April, 1995.

[17] http://www.infed.org/biblio/organizational-learning.htm accessed $31^{\text {st }}$ may 2007 [18] Van Bruggen, J. M., Boshuizen, H. P. A., \& Kirschner, P. A. (2003). A cognitive framework for cooperative problem solving with argument visualization. In P.A.Kirschner, S. J. Buckingham Shum, \& C. S. Carr (Eds.), Visualizing Argumentation: Software Tools for Collaborative and Educational Sense-Making (pp. 25-47). London: Springer.

[19] IMS learning design support for the formalization of collaborative learning patterns Leo, D.H. Perez, J.I.A. Dimitriadis, Y.A. IEEE International Conference on Advanced Learning Technologies, 2004. Proceedings. 2004. Pag. 350- 354

[20] Argyris, C.: On Organizational Learning, 1999 Blackwell Publishing [21] http://www.imsglobal.org/learningdesign/ 